(2) Open Access Full Text Article

\title{
Knowledge of, and attitudes toward, codes of ethics and associated factors among medical doctors in Addis Ababa, Ethiopia
}

This article was published in the following Dove Press journal:

Medicolegal and Bioethics

\section{Mesafint Abeje Tiruneh' Birhanu Teshome Ayele ${ }^{2}$ Kidanemariam G Michael Beyene $^{3}$}

'Health Inspectorate Directorate, Federal Ministry of Health, Addis Ababa, Ethiopia; ${ }^{2}$ Depratment of Statistics, Addis Ababa University, Addis Ababa, Ethiopia; ${ }^{3}$ Director General Office, Ethiopian Medicine and Healthcare Administration and Control Authority, Addis Ababa, Ethiopia
Correspondence: Mesafint Abeje Tiruneh Health Inspectorate Directorate, Federal Ministry of Health PO Box 1234 Addis Ababa Ethiopia

Email mesabeje@gmail.com
Background: Ethics are moral principles that attempt to determine what is morally right and wrong in human action. Professional ethics have gained significance and focus from time to time, due to increased public awareness and advancements in science and technology. Since there is limited information in Ethiopia, this study provides information about knowledge of, and attitudes toward, codes of ethics.

Objective: To assess knowledge of and attitudes toward codes of ethics and associated factors among medical doctors in Addis Ababa, Ethiopia.

Methods: An institution-based cross sectional study was conducted among 490 medical doctors in Addis Ababa from May to June 2017. Multistage sampling was used and data collected using a pretested self-administered structured questionnaire. Binary logistic regression was used for data analysis.

Results: Our study showed that 371 (75.7\%) medical doctors were knowledgeable. Sex (AOR 0.582, 95\% CI 0.357-0.951), level of education (AOR 2.048, 95\% CI 1.125-3.726), and attitudes (AOR 5.229, 95\% CI 3.300-8.286) were significantly associated with knowledge of codes of ethics. Of the total study participants, 298 (60.8\%) medical doctors had favorable attitudes toward codes of ethics. Level of education (AOR 1.321, 95\% CI 1.014 3.144), work experience (AOR 1.343, 95\% CI 1.051-3.091), and knowledge (AOR 5.208, 95\% CI 3.286-8.252) were significantly associated with attitudes toward codes of ethics.

Conclusion: A majority of medical doctors were knowledgeable about codes of ethics. Sex, level of education, and attitudes toward codes of ethics were significantly associated with knowledge of codes of ethics. A significant proportion of medical doctors had unfavorable attitudes. Level of education, work experience, and knowledge of codes of ethics were significantly associated with attitudes toward codes of ethics. As such, it is important to raise awareness and if necessary change attitudes of medical doctors toward codes of ethics. Keywords: knowledge, attitude, code of ethics, medical doctors, Addis Ababa, Ethiopia

\section{Background}

Ethics are moral principles that attempt to determine what is morally right and wrong regarding human action, and have been described as the science of morals and rules of conduct in human life. ${ }^{1-3}$ The medical code of ethics states expectations of medical doctors in their practice of medicine. 4

The growing use of technology, rapid changes in patients' attitudes toward doctors and vice versa, health-service marketing, legal action, and other factors have resulted in making the law an integral part of health care. ${ }^{5}$ Medicolegal and professional ethics aspects of health care address some of these newly raised issues. In medicine, 
professionalism indicates not only knowledge and skills but also character, especially compassion and ethics. ${ }^{6}$ Knowledge of the code of ethics and taking moral positions are an essential part of everyday medical practice. ${ }^{7}$

Professional ethics applied to medical practice date back to the earliest civilization and the Hippocratic oath. However, health professionals' codes of ethics have been developed and updated from time to time based on various contexts. ${ }^{8}$ Medical ethics principles and codes are universally accepted. However, countries can make some amendments and develop specific elucidations consistent with countries' existing culture, religion, beliefs, social norms, laws of the country, and medical practice standards in the health-care system. ${ }^{9}$

The Ethiopian Health Professionals' Code of Ethics has been developed and endorsed through regulation 299/2013 according to Food, Medicine, and Healthcare Administration and Control proclamation 661/2009. The Federal Health Professionals Ethics Committee (FHPEC) was reorganized in 2014 based on this regulation. ${ }^{10}$

Ethics have gained significance and focus from time to time due to various reasons, eg, radical changes and advances in science and technology and rapid changes in macroeconomic development. The beginning and encouragement of market economies and globalization have contributed to the increased focus being given to professional ethics in health care. ${ }^{11}$ The medical code of ethics has become a legal, moral, and basic need in all levels of medical practice. ${ }^{1}$

Despite the code of ethics, there has been growing public concern regarding the ethical conduct of medical doctors, and reports of unethical conduct of medical doctors are familiar. ${ }^{1,2}$ Medical doctors have several ethical, moral, and legal obligations in their medical practice, even if there are gaps in knowledge of and attitudes toward the code of ethics. ${ }^{12}$

According to the Ethiopian Health Professionals' Code of Ethics, medical doctors shall not provide any health service for their benefit that does not serve the needs of their patient, and they shall render the same level of care to their clients/patients in overtime and regular practice. No medical doctor shall provide any preferential treatment to a client/patient by considering the relationship established with him/her in other health institutions where the same medical doctor works. In addition, a medical doctor shall not refuse on grounds of personal belief to provide such services as contraception, legal abortion, and blood transfusions. ${ }^{10}$ The fundamental elements of the code of ethics are to respect patient autonomy and obtain informed consent, respect patient confidentiality, privacy, choices, and dignity, and provide medical service without discrimination. ${ }^{9,10}$
A study conducted in Pakistan showed that a high proportion of medical doctors (57\%) had no knowledge of a code of ethics. $^{2}$ Similarly, studies undertaken in India (Orissa and Manipur), and Nepal indicated that a very high proportion of medical doctors lacked in-depth knowledge of medical ethics, including patient autonomy and confidentiality. ${ }^{13-15}$ In addition, a study conducted in Rajasthan identified gaps in knowledge of and attitudes toward a code of ethics among medical doctors. $^{1}$

The findings of a cross-sectional study conducted in northern India indicated gaps in knowledge of practical aspects of health-care ethics, assessing confidentiality, autonomy, and informed consent as fundamental elements of a code of ethics. ${ }^{16}$ Similarly, a study conducted in Nigeria showed gaps in knowledge of health-care ethics among medical doctors. ${ }^{17}$ Another study conducted in Nigeria indicated that ethical issues dealing with confidentiality, discharge against medical advice, religion, culture, and informed consent were the most recognized by medical doctors, while their knowledge about just allocation of resources, conflict of interest, and end-of-life matters was poor. ${ }^{18}$

In Ethiopia, regulations have been endorsed and the FHPEC established to examine, investigate, and propose appropriate administrative measures on complaints made with respect to substandard health service and incompetent and unethical health professionals to take administrative measures with those who violate the code of ethics. However, complaints submitted to the FHPEC indicate that clients and patients have grievances about medical doctors' ethics. ${ }^{19}$

There is limited information in Addis Ababa regarding knowledge of and attitudes toward the code of ethics and associated factors among medical doctors. As such, this study aimed to assess such knowledge and attitudes and associated factors among medical doctors in Addis Ababa, Ethiopia.

\section{Methods}

\section{Study design, area, and period}

This institution-based cross-sectional study was conducted in Addis Ababa in May-June 2017. Addis Ababa is the diplomatic capital of the African Union and the capital of Ethiopia, with ten subcities and a total population of $3,273,001 .^{20}$ There were 26 private and 12 governmental hospitals in Addis Ababa during the study period. The standards/requirements to regulate governmental and private hospitals are the same. ${ }^{21-23}$ Specialized hospitals are regulated by the Ethiopian Food, Medicine, and Healthcare Administration and Control 
Authority (EFMHACA) and other hospitals regulated by the Addis Ababa Food, Medicine, and Healthcare Administration and Control Authority (AAFMHACA). The EFMHACA is responsible for registration, licensing, and regulation of medical doctors. ${ }^{24}$ Based on the data collected from the EFMHACA, AAFMHACA, and hospitals, there were 1,477 medical doctors working in governmental hospitals and 327 medical doctors working in private hospitals in Addis Ababa.

\section{Study population}

Study participants were medical doctors working in selected governmental and private hospitals in Addis Ababa with a minimum of 6 months of work experience.

\section{Sample-size determination and sampling procedure}

The sample size was determined using a single-population proportion formula by considering a CI, $50 \%$ proportion, $5 \%$ marginal error, design effect of 1.5 , and $10 \%$ nonresponse rate. The final sample size was 524 .

Multistage sampling was used to select the study participants. There were 1,477 medical doctors in 12 governmental hospitals and 327 medical doctors in 26 private hospitals (a total of 1,804 medical doctors) in Addis Ababa. Hospitals were stratified into governmental hospitals and private hospitals. Then, six governmental and eight private hospitals were selected by simple random sampling. A total of 429 medical doctors from six governmental hospitals and 95 medical doctors from eight private hospitals were selected by simple random sampling using proportional allocation to the number of medical doctors in each selected hospital.

\section{Data-collection tools, procedures, and quality assurance}

Data were collected using a pretested self-administered structured questionnaire. Sixteen statements of codes of ethics with multiple-choice questions were used to assess knowledge of ethics among medical doctors. Each statement was coded, computed, and the score dichotomized into knowledgeable (participants who scored $\geq 75 \%$ on knowledge-based questions) and not knowledgeable (participants who scored $<75 \%$ on knowledge-based questions). Sixteen attitude-based questions scored with five Likert scales $(0-4)$ were used to assess medical doctors' attitudes toward ethics. All attitude-based questions were coded, computed, and score categorized into favorable attitudes (participants who scored $\geq 75 \%$ on attitude- based questions) and unfavorable attitudes (participants who scored $<75 \%$ on attitude-based questions).

Seven experienced health professionals (six for data collection and one for supervision) were recruited and received 1 day's training. The collected data were checked for consistency and completeness before data analysis.

\section{Data management and analysis}

Data were coded and entered into Epi Info version 7.2.1.0 to control and manage errors resulting from data entry. The cleaned data set was exported to SPSS version 23.0 for analysis. Study participants' knowledge, attitudes, sociodemographic characteristics, and institutional factors were presented using the relevant descriptive statistics. At the $25 \%$ level of significance, univariate analysis was done to screen out potentially significant independent variables for both knowledge and attitudes. Multiple binary logistic regression was performed using the significant and relevant independent variables to determine the association between the dependent variables and independent variables at a 5\% level of significance. The adequacy of the final models for knowledge and attitudes were checked using the Hosmer-Lemeshow goodness-of-fit test, and the final models fitted the data well $(P=0.411$ and 0.754 , respectively). For binary logistic regression, 95\% CIs were calculated, with $P \leq 0.05$ considered statistically significant.

\section{Ethics approval and consent to participate}

The study was approved by Gamby Medical and Business College, Addis Ababa Health Bureau and St Paul Specialized Hospital Millennium Medical College Research ethics review committees. In addition, prior to data collection, permission was obtained from all selected hospitals. Written consent was obtained from study participants after briefing them on the objectives of the study. Personal identifiers, such as name of study participants, were not registered in the data-collection tool to ensure confidentiality. Consent for publication was obtained from all study participants during data collection.

\section{Results}

\section{Sociodemographic characteristics}

Of the 524 medical doctors, 490 responded, for a response rate of $93.5 \%$. A majority $(306,61.2 \%)$ were male, and half were aged25-29 years. A total of 312 (63.7\%) study participants were Orthodox Tewahedo Christians, and 317 $(64.7 \%)$ were general practitioners. A majority (307, $62.7 \%$ ) were satisfied in their work (Table 1). 
Table I Sociodemographic characteristics of medical doctors in Addis Ababa, $2017(n=490)$

\begin{tabular}{|l|l|l|}
\hline Variables & $\mathbf{n}$ & $\%$ \\
\hline Sex & 302 & \\
Male & 188 & 61.6 \\
Female & & 38.4 \\
\hline Age, years & 249 & \\
$25-29$ & 142 & 50.8 \\
$30-34$ & 99 & 29.0 \\
$>34$ & & 20.2 \\
\hline Religion & 312 & \\
Orthodox Tewahedo & 22 & 63.7 \\
Catholic & 82 & 4.5 \\
Protestant & 55 & 16.7 \\
Muslim & 19 & 11.2 \\
Others* & & 3.9 \\
\hline Level of education & 317 & \\
General practitioner & 173 & 64.7 \\
Specialist & & 35.3 \\
\hline Work experience, years & 228 & \\
<4 & 179 & 46.5 \\
4-7.9 & 83 & 36.5 \\
28 & & 16.9 \\
\hline Level of satisfaction & & \\
Satisfied & & \\
Dissatisfied & & \\
\hline
\end{tabular}

Note: *Including Jehovah's Witness, Wakefeta, and unspecified religions.

\section{Institutional factors}

Of study participants, 413 (84.3\%) were from governmental hospitals, and $449(91.6 \%)$ took courses on medical ethics during their medical education. A majority (409, $83.5 \%$ ) had not taken any in-service training on codes of ethics/medical ethics (Table 2).

Table 2 Institutional factors for practice of code of ethics among medical doctors in Addis Ababa, 2017 ( $n=490)$

\begin{tabular}{|l|l|l|}
\hline Variables & $\mathbf{n}$ & $\%$ \\
\hline $\begin{array}{l}\text { Type of hospital } \\
\text { Governmental }\end{array}$ & 413 & 84.3 \\
Private & 77 & 15.7 \\
\hline Took medical ethics course & & \\
Yes & 449 & 91.6 \\
No & 41 & 8.4 \\
\hline Had training on code of ethics/medical ethics & & \\
Yes & 81 & 16.5 \\
No & 409 & 83.5 \\
\hline
\end{tabular}

\section{Knowledge about the existence of code} of ethics and FHPEC

Among participants, 365 (74.5\%) knew that Ethiopia had a Health Professionals Code of Ethics and 275 (56.1\%) knew of the existence of FHPEC. Of the latter, 180 $(65.5 \%)$ of them did not know the powers and duties of the FHPEC (Table 3).

\section{Knowledge of code of ethics}

Of 490 medical doctors, 371 (75.7\%, 95\% CI 71.6\%$79.4 \%$ ) were knowledgeable and the remaining 119 (24.3\%, 95\% CI 20.6\%-28.4\%) not knowledgeable about the code of ethics.

\section{Factors associated with knowledge of code of ethics}

Univariate analysis of the independent variables sex, level of education, training, and attitudes revealed significant associations with knowledge of the code of ethics among medical doctors at a $25 \%$ level of significance. However, only sex, level of education and attitudes were found to be significantly associated with code of ethics knowledge in the multiple logistic regression model at a 5\% level of significance.

Accordingly, male medical doctors were less likely to be knowledgeable about the code of ethics than female medical doctors (AOR 0.582, 95\% CI 0.357-0.951).

Level of education was significantly associated with code of ethics knowledge. Specialist medical doctors were 2.048 times more likely to be knowledgeable about this than general practitioners (AOR 2.048, 95\% CI 1.1253.726).

Table 3 Knowledge about existence of code of ethics and FHPEC among medical doctors in Addis Ababa, 2017 ( $n=490)$

\begin{tabular}{|l|l|l|}
\hline Variables & $\mathbf{n}$ & $\%$ \\
\hline $\begin{array}{l}\text { Knowledge about existence of } \\
\text { code of ethics } \\
\text { Yes }\end{array}$ & & \\
No & 365 & 74.5 \\
\hline Knowledge about existence of FHPEC & 125 & 25.5 \\
Yes & 275 & \\
No & 215 & 56.1 \\
\hline Knowledge about powers and duties of & & \\
FHPEC (n=275) & & \\
Yes & 95 & 34.9 \\
No & 180 & 65.5 \\
\hline
\end{tabular}

Abbreviation: FHPEC, Federal Health Professionals Ethics Committee. 
Medical doctors with favorable attitudes were 5.229 times more likely to be knowledgeable about the code of ethics than medical doctors with unfavorable attitudes (AOR 5.229, 95\% CI 3.300-8.286; Table 4).

\section{Attitudes toward code of ethics}

Of all study participants, 298 (60.8\%, 95\% CI 56.5\%$65.3 \%$ ) of medical doctors had favorable attitudes and the remaining $192(39.2 \%, 95 \%$ CI $34.7 \%-43.5 \%)$ unfavorable attitudes toward the code of ethics (Table 5).

\section{Factors associated with attitudes}

Univariate analysis of the independent variables age, level of education, type of hospital, work experience, level of satisfaction, and knowledge revealed significantly associations with code of ethics knowledge among medical doctors at a $25 \%$ level of significance. However, only level of education, work experience, and knowledge were found to be significantly associated with same in the multiple logistic regression model at a $5 \%$ level of significance.

Accordingly, specialist medical doctors were 1.321 times more likely to have favorable attitudes toward the code of ethics than general practitioners (AOR 1.321, 95\% CI 1.014-3.144)

Medical doctors who had $>8$ years of work experience were 1.343 times more likely to have favorable attitudes tthan those with 4-8years of work experience (AOR 1.343, 95\% CI 1.051-3.091).

Knowledgeable medical doctors were 5.208 times more likely to have favorable attitude than those not

Table 4 Univariate and multivariate analysis of factors associated with knowledge of code of ethics among medical doctors in Addis Ababa, $2017(n=490)$

\begin{tabular}{|c|c|c|c|c|c|}
\hline \multirow[t]{2}{*}{ Variables } & \multicolumn{2}{|l|}{ Knowledge } & \multirow[t]{2}{*}{ COR $(95 \% \mathrm{Cl})$} & \multirow[t]{2}{*}{ AOR (95\% CI) } & \multirow[t]{2}{*}{$P$-value } \\
\hline & Knowledgeable & Not knowledgeable & & & \\
\hline \multicolumn{6}{|l|}{ Sex } \\
\hline Male & 217 & 85 & $0.564(0.360-0.882)$ & $0.582(0.357-0.95 I)$ & $0.031 *$ \\
\hline Female & 154 & 34 & 1.00 & 1.00 & \\
\hline \multicolumn{6}{|l|}{ Age, years } \\
\hline $25-29$ & 191 & 58 & $0.997(0.612-1.624)$ & $\mathrm{I} .28 \mathrm{I}(0.704-2.33 \mathrm{I})$ & $0.48 I$ \\
\hline $30-34$ & 109 & 33 & 1.00 & 1.00 & \\
\hline$>34$ & 71 & 28 & 0.768 (0.427-1.379) & $1.219(0.506-2.936)$ & 0.659 \\
\hline \multicolumn{6}{|l|}{ Level of education } \\
\hline General practitioner & 233 & 84 & & & \\
\hline Specialist & 138 & 35 & $1.421(0.909-2.223)$ & $2.048(1.125-3.726)$ & $0.019 *$ \\
\hline \multicolumn{6}{|l|}{ Type of hospital } \\
\hline Governmental & 314 & 99 & $1.113(0.637-1.943)$ & $0.792(0.4|0-| .53 \mid)$ & 0.488 \\
\hline Private & 57 & 20 & 1.00 & 1.00 & \\
\hline \multicolumn{6}{|l|}{ Work experience } \\
\hline$<4$ years & 175 & 53 & $1.012(0.637-1.608)$ & $1.243(0.7 \mid 8-2.153)$ & 0.436 \\
\hline $4-7.9$ years & 137 & 42 & 1.00 & 1.00 & \\
\hline$\geq 8$ years & 59 & 24 & $0.754(0.419-1.356)$ & $0.666(0.264-1.678)$ & 0.389 \\
\hline \multicolumn{6}{|l|}{ Training } \\
\hline No & 316 & 93 & 1.00 & 1.00 & \\
\hline Yes & 55 & 26 & $0.623(0.370-1.048)$ & $0.632(0.35 \mathrm{I}-\mathrm{I} .137)$ & 0.126 \\
\hline \multicolumn{6}{|l|}{ Level of satisfaction } \\
\hline Satisfied & 231 & 76 & $0.934(0.608-1.434)$ & $0.84 \mid(0.522-\mid .356)$ & 0.478 \\
\hline Dissatisfied & 140 & 43 & 1.00 & 1.00 & \\
\hline \multicolumn{6}{|l|}{ Attitude } \\
\hline Favorable & 260 & 38 & $4.993(3.200-7.790)$ & $5.229(3.300-8.286)$ & $<0.001 *$ \\
\hline Unfavorable & 111 & 81 & 1.00 & 1.00 & \\
\hline
\end{tabular}

Note: COR, Crude odds ratio; AOR, Adjusted odds ratio; $\mathrm{Cl}$, Confidence interval; *Statistically significant on multivariate analysis. 


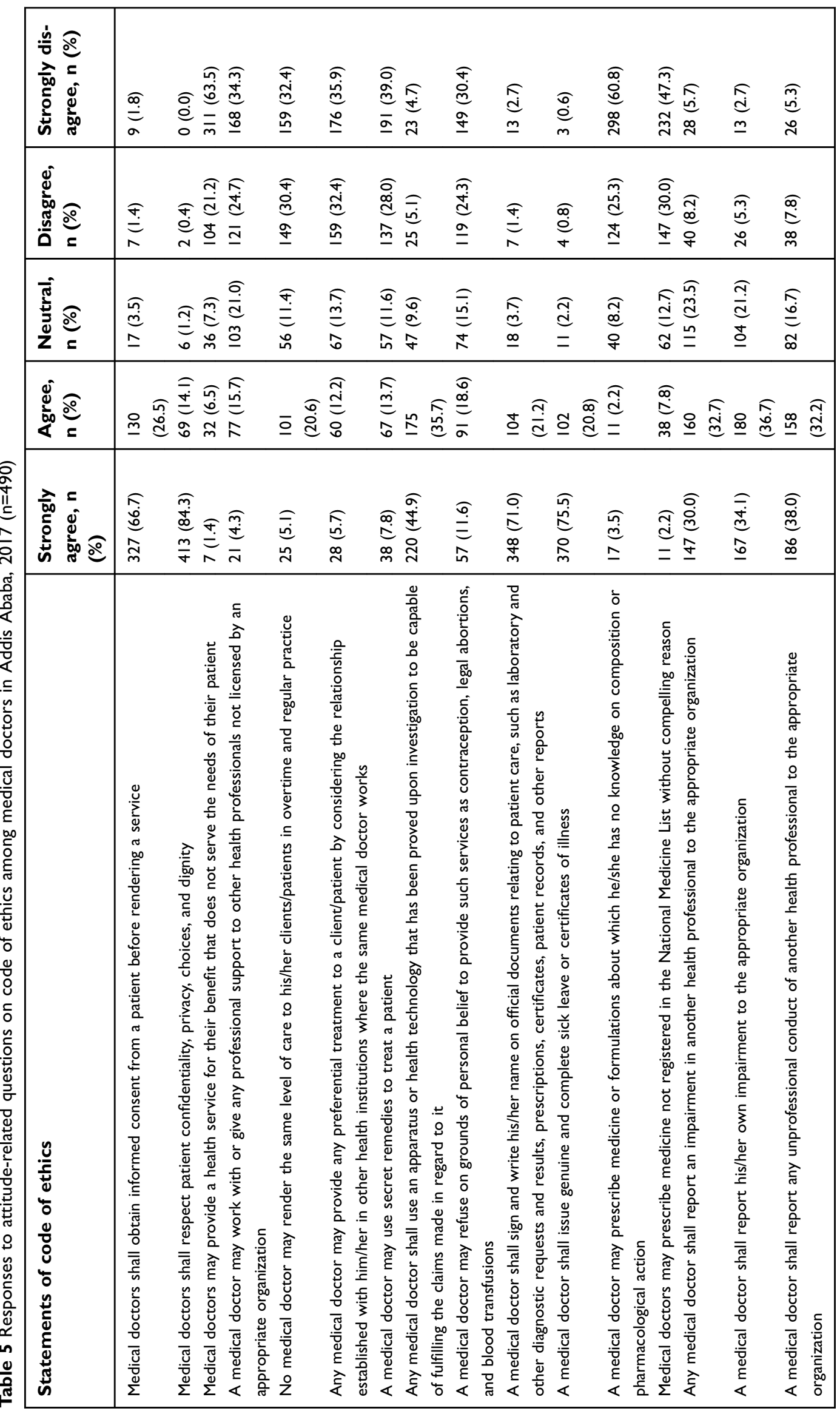


knowledgeable (AOR 5.208, 95\% CI $3.286-8.252$ ) (Table 6).

The findings of this study will provide information about knowledge of and attitudes toward codes of ethics and associated factors among medical doctors for responsible stakeholders to develop policy and strategies to reduce gaps in knowledge and attitudes.

\section{Discussion}

The main purpose of this study was to assess knowledge of and attitudes toward the Ethiopian code of ethics and associated factors among medical doctors in Addis Ababa. The study revealed that 371 (75.7\%) of the medical doctors had said knowledge. Gaps in knowledge might affect the quality of medical service and patient safety. Our findings were higher than studies conducted in Manipur, India (30.1\%), Pakistan (43\%), Orissa, India (52\%), Barbados (52\%), and Nigeria $(66.8 \%))^{2,13,18,25,26}$ This might be due to the difference in education systems and health-care settings.

The findings of this study identified that sex was significantly associated with knowledge. Male medical doctors were less likely to know about the code of ethics than female medical doctors.

The other determinant of knowledge was level of education. Specialist medical doctors were about twice as likely to know about the code of ethics as general practitioners. This might be due to specialist medical doctors having better work experience, medical practice, and exposure to medical ethics during their specialization.

Table 6 Univariate and multivariate analysis of factors associated with attitudes toward codes of ethics among medical doctors in Addis Ababa, $2017(n=490)$

\begin{tabular}{|c|c|c|c|c|c|}
\hline \multirow[t]{2}{*}{ Variables } & \multicolumn{2}{|l|}{ Attitude } & \multirow[t]{2}{*}{ COR $(95 \% \mathrm{CI})$} & \multirow[t]{2}{*}{ AOR (95\% Cl) } & \multirow[t]{2}{*}{$P$-value } \\
\hline & Favorable & Unfavorable & & & \\
\hline \multicolumn{6}{|l|}{ Sex } \\
\hline Male & 181 & 121 & $0.908(0.624-1.320)$ & $1.096(0.724-1.658)$ & 0.666 \\
\hline Female & 117 & 71 & 1.00 & 1.00 & \\
\hline \multicolumn{6}{|l|}{ Age, years } \\
\hline $25-29$ & 148 & 101 & $0.702(0.455-1.083)$ & $0.833(0.486-1.425)$ & 0.504 \\
\hline $30-34$ & 96 & 46 & 1.00 & 1.00 & \\
\hline$>34$ & 54 & 45 & $0.575(0.339-0.976)$ & $0.472(0.2 \mid 4-1.042)$ & 0.063 \\
\hline \multicolumn{6}{|l|}{ Level of education } \\
\hline General practitioner & 186 & 131 & 1.00 & 1.00 & \\
\hline Specialist & 112 & 61 & $1.293(0.881-1.898)$ & $1.321(1.014-3.144)$ & $0.025^{*}$ \\
\hline \multicolumn{6}{|l|}{ Type of hospital } \\
\hline Governmental & 257 & 156 & $\mathrm{I} .447(0.886-2.36 \mathrm{I})$ & $1.462(0.829-2.576)$ & 0.189 \\
\hline Private & 41 & 36 & 1.00 & 1.00 & \\
\hline \multicolumn{6}{|l|}{ Work experience } \\
\hline$<4$ years & 133 & 95 & $0.742(0.495-1.112)$ & $0.752(0.460-1.227)$ & 0.254 \\
\hline $4-7.9$ years & 117 & 62 & 1.00 & 1.00 & \\
\hline$\geq 8$ years & 48 & 35 & $0.727(0.426-1.239)$ & $1.343(1.05 I-3.09 I)$ & $0.035^{*}$ \\
\hline \multicolumn{6}{|l|}{ Training } \\
\hline No & 250 & 159 & 1.00 & 1.00 & \\
\hline Yes & 48 & 33 & $0.925(0.569-1.504)$ & $1.069(0.621-1.839)$ & 0.809 \\
\hline \multicolumn{6}{|l|}{ Level of satisfaction } \\
\hline Satisfied & 193 & 114 & $1.258(0.866-1.827)$ & $1.356(0.90 \mathrm{I}-2.040)$ & 0.144 \\
\hline Dissatisfied & 105 & 78 & 1.00 & 1.00 & \\
\hline \multicolumn{6}{|l|}{ Knowledge } \\
\hline Knowledgeable & 260 & 111 & $4.993(3.200-7.790)$ & $5.208(3.286-8.252)$ & $<0.00 I^{*}$ \\
\hline Not knowledgeable & 38 & 81 & 1.00 & 1.00 & \\
\hline
\end{tabular}

Note: *Statistically significant on multivariate analysis. 
Another possible reason might be that specialist medical doctors have the opportunity to share best practices and experiences with foreign medical doctors and attain continuing medical education from other countries. This finding is similar to a study conducted in Rajasthan, which indicated that medical doctors with specialization had more eithics knowledge than general medical practitioners. ${ }^{1}$

Our study indicated that attitudes toward the code of ethics was one of the determinants of knowledge of same among medical doctors. Medical doctors who had favorable attitudes were about five times as likely to know the code of ethics as medical doctors who had unfavorable attitudes. A possible reason might be medical doctors who have favorable attitudes to the code of ethics might be eager to understand and practice itproperly.

A considerable number of medical doctors (60.8\%) had favorable attitudes. However, a significant number of medical doctors in governmental and private hospitals in Addis Ababa had unfavorable attitudes. Unfavorable attitudes were due to the fact that medical doctors believed they did not render the same level of care to their patients in overtime and regular practice and provided preferential treatment to clients/patients as a result of their relationship established in other health institution. Also, medical doctors agreed to refuse provision of medical services, such as contraception, legal abortion, and blood transfusions, on grounds of personal belief and disagreed to report any unprofessional conduct of other health professionals to the appropriate organization. Patient safety and quality of medical service might be compromised due to unfavorable attitudes of medical doctors toward the code of ethics.

The results of this study showed that level of education was one of the factors significantly associated with attitudes. Specialist medical doctors were 1.3 times as likely to have favorable attitudes than general practitioners. A possible explanation might be that specialist medical doctors are expected to be role models for others relating to their educational status and experience. Also, the exposure of general medical practitioners to the code of ethics may be low with a lack of inservice training as part of continuing professional development compared to specialist medical doctors. This is similar to a study conducted in Rajasthan, where medical doctors with specialization had more favorable attitudes regarding ethics than general medical practitioners. ${ }^{1}$

On the other hand, duration of work experience was significantly associated with attitudes. Medical doctors with $>8$ years of work experience were 1.3 times as likely to have favorable attitudes than medical doctors who had 4-8 years of work experience. This might be due to the fact that medical doctors who have long work experience in medical practice may recognize the importance of the code of ethics. Similarly, studies conducted in Rajasthan and Bavaria showed significant associations between attitudes and duration of work experience. ${ }^{1,27}$

Our study also indicated that knowledgeable medical doctors were about five times as likely to have favorable attitudes than those who had no knowledge. A possible reason might be that knowledgeable medical doctors were able properly to understand the content and importance of a code of ethics.

Medical doctors should consider their duties and obligations and how best they may be met. The outcome of the medical service they provide may not be sufficient to explain their action. This approach considers the promise as a duty, a breach of which requires specific justification involving a conflict of dutie: the duty to keep the promise against the duty to do what is in the best interest of the patient/client. ${ }^{28}$ The breach might be related to gaps in knowledge and attitudes.

Gaps in knowledge of and attitudes toward codes of ethics in medical practice might contribute to poor ethical practice. This might compromise the provision of quality medical services and patient safety. It could result in worsening health conditions, failure to treat initial health conditions, development of other health problems and complications, increased medical expenses, disability, and death. Furthermore, this might lead to loss of confidence and trust in health services and medical doctors. ${ }^{29,30}$

\section{Conclusion}

A majority of medical doctors working in governmental and private hospitals in Addis Ababa had knowledge of the local medical code of ethics. Sex, level of education, and attitudes toward the code were significantly associated with knowledge of the code. Furthermore, a significant proportion of medical doctors had unfavorable attitudes. Level of education, work experience, and knowledge were significantly associated with attitudes. 
Therefore, it is necessary to increase awareness of medical doctors and change their attitudes toward ethics by providing on-the-job training and strengthening integration of medical ethics courses within medical education. It is also important to establish a system that can help identify the root causes of frequently lodged complaints related to ethical violations to provide sustainable solutions and improve the quality of medical service and patient safety. Finally, we recommend further research be conducted using focus-group discussions to minimize a social desirability-response bias, which was considered a limitation of this study.

\section{Availability of data and material}

All relevant data and material are available within the manuscript.

\section{Abbreviations}

AAFMHACA, Addis Ababa Food, Medicine, and Healthcare Administration and Control Authority; EFMHACA, Ethiopian Food, Medicine, and Healthcare Administration and Control Authority; EMA, Ethiopian Medical Association; FHPEC, Federal Health Professionals Ethics Committee; FMoH, Federal Ministry of Health

\section{Acknowledgments}

The authors would like to thank the data collectors and supervisors for their collaboration during the data collection. We would also like to thank study participants for their participation. The authors received no specific funding for this work.

\section{Author contributions}

All authors contributed to data analysis, drafting and revising the article, gave final approval of the version to be published, and agree to be accountable for all aspects of the work.

\section{Disclosure}

The authors report no conflicts of interest in this work.

\section{References}

1. Anup N, Himanshu K, Gautam B, et al. Knowledge, attitude \& practices regarding ethics \& law amongst medical and dental professionals in Rajasthan - a questionnaire study. Iosr Jdms. 2014;13 (5):102-109. doi:10.9790/0853-1354102109

2. Nazish I, Imran I, Masood J, et al. Health ethics education: knowledge, attitudes and practice of healthcare ethics among interns and residents in Pakistan. JPMI. 2014;28(4):383-389.
3. Thomas A, David G. Biomedical Ethics. 4th ed. New York: Mc Graw-Hill; 1996.

4. Australian Medical Council. Good Medical Practice: A Code of Conduct for Doctors in Australia. Australian Medical Council, July 2009.

5. Sanjay P. Law, ethics and medical practice. Indian J Med Ethics. 2005;2(1):2.

6. Moser RH. A few thoughts about professionalism (editorial). $S$ Med J. 2000;93:1132-1133. doi:10.1097/00007611-200011000-00021

7. Beauchamp T, Childress J. Principles of Biomedical Ethics. 6 ed. Oxford: Oxford University Press; 2008.

8. Sauer JE. Ethical Problems Facing the Industry. Hosp Health Serv Administration. 1985;30:44-53.

9. Ethiopian Medical Association. Medical Ethics for Doctors in Ethiopia. Addis Ababa, Ethiopia: Ethioipian Medical Association (EMA);2010.

10. Federal Democratice Republic of Ethiopia, The House of Peoples Representatives. Food, medicine and healthcare administratuion and control council of ministers regulation no. 299/2013. Fed Negarit Gazeta. 2014;11(24):7210.

11. World Health Organization, Regional Office for South-East Asia. Health Ethics in Six SEAR Countries. Health Ethics Is South-East Asia Volume 1. New Delhi, India.

12. Nanandkar SD. Assessment of medico legal awareness of practicing obstetricians \& gynecologists. JIAFM. 2008;30(3):136.

13. Shreemanta K. Medical ethics, duties \& medical negligence awareness among the practitioners in a teaching medical college, hospital-a survey. J Indian Acad Forensic Med. 2005;32(2):153.

14. Akoijam Brogen S, Rajkumari B, Laishram J, Joy A. Knowledge and attitudes of doctors on medical ethics in a teaching hospital, Manipur. Indian J Med Ethics. 2009;VI(4):7.

15. Samaj A, Kumar P, Arja R, et al. Knowledge, attitude and practice of healthcare ethics among resident doctors and ward nurses from a resource poor setting, Nepal. BMC Med Ethics. 2016;17:68. doi:10.1186/s12910-016-0130-4

16. Mukul C, Anu B, Prassana M, et al. Current status of knowledge, attitudes and practices towards healthcare ethics among doctors and nurses from northern india - a multicentre study. Jkimsu. 2013;2(2):102.

17. Kehinde F, Tajudeen O, Abdulrasheed A, et al. Medical ethics in SubSahara Africa: closing the gaps. Afr Health Sci. 2015;15(2):673-681. doi:10.4314/ahs.v15i2.47

18. Joseph O, Olufemi O, Abiodun C, et al. Knowledge of medical ethics among Nigerian medical doctors. Niger Med J. 2012;53(4):226-230. doi:10.4103/0300-1652.107600

19. Biruk L, Mesafint A, Yeweyenhareg F, et al. Analysis of medical malpractice claims and measures proposed by the health professionals ethics federal committee of ethiopia: review of the three years proceedings. Ethiop Med J. 2015;53(Supp):1.

20. Federal Demcratic Republic of Ethiopian, Ministry of Health. Health and Health Related Indicators. Addis Ababa, Ethiopia;2016:11

21. Ethiopian Standard Agency. Primary Hospital Requirements. Addis Ababa, Ethiopia: Universal Priniting Press; 2012.

22. Ethiopian Standard Agency. General Hospital Requirements. Vol. ES3614. Addis Ababa, Ethiopia: Universal Printing Press; 2012.

23. Ethiopian Standard Agency. Comprehensive Specialized Hospital Requirements. Addis Ababa, Ethiopia: Universal Printing Proess; 2012.

24. Federal Demcratic Republic of Ethiopian, The House of Peoples Representatives. Food, medicine and healthcare administratuion and control proclamation no. 661/2009. Fed Negarit Gazeta. 2010;9(13):5180.

25. Akoijam B, Bishwalata R, Jalina L, et al. Knowledge and attitudes of doctors on medical ethics in a teaching hospital, Manipur. Indian $J$ Med Ethics. 2009;6(4):194-197. doi:10.20529/IJME.2009.066

26. Seetharaman H. Knowledge, attitudes and practice of healthcare ethics and law among doctors and nurses in Barbados. BMC Med Ethics. 2006;7:7. doi:10.1186/1472-6939-7-7 
27. Jana W, Tibor S, Wolfgang S, et al. Medical ethical knowledge and moral attitudes among physicians in Bavaria. Dtsch Arztebl Int. 2012;109(8):141-147. doi:10.3238/arztebl.2012.0141

28. Ray N. Introduction to medical ethics: medical ethics in the 'Global village'. In: Centre for Reproductive Ethics and Rights UCL Institute for Women's Health. London; 2007:9.
29. Hach and Rose, LLP. Consequences of medical malpractice. 2017; Available from: https://www.unionlawfirm.com/articles/conse quences-of-medical-malpractice/. Accessed September 10, 2017.

30. Semien and Semien, LLC. Consequence of medical malpractice; 2017 Available from: http://www.simien.com/malpractice-conse quences.html. Accessed September 10, 2017.

\section{Publish your work in this journal}

Medicolegal and Bioethics is an international, peer-reviewed, open access journal exploring the application of law to medical and drug research and practice and the related ethical and moral considerations. The journal is characterized by the rapid reporting of reviews, case reports, guidelines and consensus statements, original research and surveys. The manuscript management system is completely online and includes a very quick and fair peer-review system. Visit http://www.dovepress.com/testimonials.php to read real quotes from published authors. 